\title{
No association between a candidate TCF7L2 variant and risk of
} breast or ovarian cancer

\author{
Ellen L Goode*†1, Csilla Szabo ${ }^{\dagger 4}$, Ludmila Prokunina-Olsson², \\ Robert A Vierkant ${ }^{1}$, Zachary S Fredericksen ${ }^{1}$, Francis S Collins ${ }^{3}$, \\ Kristin L White ${ }^{1}$, Michele Schmidt ${ }^{1}$, Brooke L Fridley ${ }^{1}$ and Fergus J Couch ${ }^{4}$
}

Address: ${ }^{1}$ Health Sciences Research, Mayo Clinic College of Medicine, Rochester, USA, ${ }^{2}$ Laboratory of Translational Genomics, Division of Cancer Epidemiology and Genetics, National Cancer Institute, National Institutes of Health, Bethesda, USA, ${ }^{3}$ Office of the Director, National Institutes of Health, Bethesda, USA and ${ }^{4}$ Laboratory Medicine and Pathology, Mayo Clinic College of Medicine, Rochester, USA

Email: Ellen L Goode* - egoode@mayo.edu; Csilla Szabo - szabo.csilla@mayo.edu; Ludmila Prokunina-Olsson - prokuninal@mail.nih.gov; Robert A Vierkant - vierkant.robert@mayo.edu; Zachary S Fredericksen - Fredericksen.zachary@mayo.edu;

Francis S Collins - Francis.Collins@nih.gov; Kristin L White - white.kristin@mayo.edu; Michele Schmidt - schmidt.michele1@mayo.edu; Brooke L Fridley - fridley.brooke@mayo.edu; Fergus J Couch - couch.fergus@mayo.edu

* Corresponding author †Equal contributors

Published: 4 September 2009

BMC Cancer 2009, 9:3/2 doi:10.1|86/|47|-2407-9-3/2
Received: 8 May 2009

Accepted: 4 September 2009

This article is available from: http://www.biomedcentral.com/I47I-2407/9/3/2

(C) 2009 Goode et al; licensee BioMed Central Ltd.

This is an Open Access article distributed under the terms of the Creative Commons Attribution License (http://creativecommons.org/licenses/by/2.0), which permits unrestricted use, distribution, and reproduction in any medium, provided the original work is properly cited.

\begin{abstract}
Background: TCF7L2 is a transcription factor involved in $\mathrm{Wnt} / \beta$-catenin signaling which has a variant known to be associated with risk of Type 2 diabetes and, in some studies, with risk of certain cancers, including familial breast cancer. No studies of ovarian cancer have been reported to date.
\end{abstract}

Methods: Two clinic-based case-control studies at the Mayo Clinic were assessed including 798 breast cancer cases, 843 breast cancer controls, 39I ovarian cancer cases, and 458 ovarian cancer controls. Genotyping at TCF7L2 rs 12255372 used a 5' endonuclease assay, and statistical analysis used logistic regression among participants as a whole and among a priori-defined subsets.

Results: No associations with risk of breast or ovarian cancer were observed (ordinal model, $p=$ 0.62 and $p=0.75$, respectively). In addition, no associations were observed among sub-groups defined by age, BMI, family history, stage, grade, histology, or tumor behavior.

Conclusion: Although the biology of the $\mathrm{Wnt} / \beta$-catenin signaling pathway and prior association between rs 12255372 and numerous phenotypes warranted examination of this TCF7L2 SNP, no compelling evidence for association with breast or ovarian cancer was observed.

\section{Background}

Transcription factor 7-like 2 (TCF7L2) encodes a transcription factor involved in Wnt/ $\beta$-catenin signaling pathway which encompasses an intronic single-nucleotide polymorphism (SNP, rs12255372) that has been associated with risk of Type 2 diabetes in linkage studies and genome-wide association studies [1-4] with potential modification by obesity [5]. TCF7L2 forms an active nuclear complex with $\beta$-catenin that binds and induces the expression of target genes involved in cellular proliferation, evasion of apoptosis, and tissue invasion and metastasis. Because of the protein's relevance in this 
canonical cancer pathway, several cancer association studies have been conducted. Studies report associations with increased risk of familial breast cancer [6] and aggressiveness of prostate cancer [7]; there are conflicting reports in colon cancer showing decreased risk [8], increased risk [9], or differential risk by NSAIDs use [10]. We sought to assess the role of this polymorphism in risk of breast and ovarian cancer and, based on other reports, in subsets defined by body mass index (BMI), family history, and measures of disease aggressiveness (e.g., stage, histological subtypes).

\section{Methods}

Female participants were recruited at Mayo Clinic in Rochester, MN. Invasive breast cancer cases $(\mathrm{N}=798)$ were over 18 years of age and enrolled within six months of diagnosis. Invasive or borderline epithelial ovarian cancer cases $(\mathrm{N}=391)$ were over 20 years of age and living in the Upper Midwest enrolled within one year of diagnosis. Controls (breast cancer $\mathrm{N}=843$; ovarian cancer $\mathrm{N}=458$ ) were frequency-matched on age and region of residence and seen for general medical examinations. Risk factor information was collected through interviews, clinical data was abstracted from medical records, and DNA was extracted from peripheral blood (Gentra). All breast cancer participants and $98 \%$ of ovarian cancer participants were white non-Hispanic. Details are provided elsewhere $[11,12]$.

Genotyping at TCF7L2 rs12255372 was performed on 384-well plates using TaqMan ${ }^{\mathrm{TM}}$ (Applied Biosystems). For breast and ovarian cancer, respectively, call rates were high $(98.1 \%, 95.9 \%)$, genotypes were in Hardy-Weinberg equilibrium ( $\mathrm{p}=0.23, \mathrm{p}=0.96$, white non-Hispanic control minor allele frequencies were as expected $(27.6 \%$, $26.0 \%$ ), and concordance across duplicates was $100 \%$. Logistic regression in SAS v. 8 (SAS Institute) was used to estimate odds ratios (ORs) and 95\% confidence intervals (CIs), primarily assuming an ordinal effect with simple tests for trend; heterozygous and minor allele homozygous ORs were also estimated. Ovarian cancer analyses were adjusted for age and region of residence; breast cancer analyses were additionally adjusted for oral contraceptive use, hormone therapy use, age at first birth, age at menarche, menopausal status, and smoking pack years. Stratified analyses were performed on sub-groups of menopausal status, BMI, family history, and estrogen, progesterone, and HER2 receptor status (breast cancer) and age, family history, BMI, stage, grade, histology, and tumor behavior (ovarian cancer).

\section{Results}

For both breast and ovarian cancer, no overall association with risk was observed (per-allele OR, 95\% CI; breast 1.04, 0.89-1.22; ovarian 0.96, 0.77-1.20). Breast cancer stratified analyses revealed no associations (p's > 0.05) among groups defined by menopausal status, BMI, family history, or tumor histology (Table 1). Assuming independent genotype effects (co-dominance), differential risk of breast cancer by genotype for HER2 positive was suggested (GT vs GG 1.68, 1.12-2.53; TT vs GG 0.49, 0.17 $1.45 ; 2$ d.f. $\mathrm{p}=0.01$ ). Exploratory analyses assuming dominance (GT/TT v GG) suggested elevated breast cancer risks for pre-menopausal $(1.46,0.99-2.15 ; \mathrm{p}=0.06)$, HER2 positive $(1.48,1.00-2.01 ; \mathrm{p}=0.05)$, and triple negative cases $(2.01,1.10-3.67 ; \mathrm{p}=0.02)$. Although sub-

Table I: TCF7L2 rs 12255372 and risk of breast cancer

\begin{tabular}{|c|c|c|c|c|c|c|c|c|}
\hline & & \multirow{2}{*}{$\begin{array}{c}\mathbf{N} \\
\text { Cases }\end{array}$} & \multirow{2}{*}{$\begin{array}{c}\mathbf{N} \\
\text { Controls }\end{array}$} & \multicolumn{2}{|c|}{ Ordinal OR (95\% CI) } & \multicolumn{3}{|c|}{ Co-Dominant ORs (95\% Cl) } \\
\hline & & & & Per T-allele & $P$ (trend) & GT v GG & TT v GG & $P(2$ d.f.) \\
\hline Total & --- & 779 & 830 & $1.04(0.89-1.22)$ & 0.62 & $1.16(0.93-1.43)$ & $0.92(0.62-1.36)$ & 0.31 \\
\hline Menopausal & Pre & 268 & 213 & $1.28(0.94-1.75)$ & 0.12 & $1.51(1.01-2.26)$ & $1.21(0.56-2.61)$ & 0.14 \\
\hline status & Post & 467 & 573 & $0.95(0.77-1.16)$ & 0.59 & $1.03(0.78-1.34)$ & $0.79(0.49-1.29)$ & 0.60 \\
\hline \multirow[t]{2}{*}{ BMI } & $\leq 25.9$ & 341 & 394 & $1.07(0.84-1.37)$ & 0.59 & $1.25(0.90-1.73)$ & $0.91(0.50-1.64)$ & 0.34 \\
\hline & $>25.9$ & 406 & 393 & $1.03(0.82-1.30)$ & 0.78 & $1.13(0.83-1.54)$ & $0.92(0.52-1.63)$ & 0.66 \\
\hline Family & No & 424 & 480 & $1.04(0.84-1.30)$ & 0.70 & $1.09(0.81-1.46)$ & $1.02(0.60-1.73)$ & 0.85 \\
\hline history & Yes & 336 & 312 & $0.99(0.77-1.28)$ & 0.95 & $1.25(0.89-1.76)$ & $0.68(0.36-1.28)$ & 0.14 \\
\hline Estrogen & Positive & 472 & 830 & $1.09(0.9|-| .3 \mid)$ & 0.34 & $1.16(0.90-1.49)$ & $1.10(0.70-1.7 I)$ & 0.50 \\
\hline Receptor (ER) & Negative & 107 & 830 & $1.11(0.81-1.52)$ & 0.52 & $1.41(0.92-2.17)$ & $0.84(0.36-1.96)$ & 0.21 \\
\hline Progesterone & Positive & 429 & 830 & $1.21(0.93-1.35)$ & 0.23 & $1.19(0.92-1.54)$ & $1.15(0.73-1.81)$ & 0.39 \\
\hline Receptor (PR) & Negative & 147 & 830 & $1.00(0.76-1.32)$ & 0.99 & $1.19(0.82-1.71)$ & $0.74(0.35-1.56)$ & 0.40 \\
\hline \multirow{2}{*}{ HER2 status } & Positive & 122 & 830 & $1.14(0.83-1.55)$ & 0.42 & $1.68(1.12-2.53)$ & $0.49(0.17-1.45)$ & 0.01 \\
\hline & Negative & 269 & 830 & $1.02(0.82-1.27)$ & 0.85 & $1.04(0.78-1.40)$ & 1.01 (0.60-1.70) & 0.96 \\
\hline ER, PR, HER2 & All Negative & 51 & 842 & $1.47(0.95-2.26)$ & 0.08 & $2.16(1.16-4.01)$ & $1.36(0.43-4.30)$ & 0.05 \\
\hline
\end{tabular}

BMI, body mass index, categorized by median value; family history, first-degree or second-degree family history; analyses adjusted for age, region of residence, oral contraceptive use, hormone therapy use, age at first birth, age at menarche, menopausal status (unless used as stratifiying variable), and pack years of smoking; n.a., not estimatable, bold indicates $p<0.05$. 
groups were limited in size, these results are consistent with involvement of rs12255372 in non-luminal tumors. Analyses among ovarian cancer sub-groups did not suggest varied associations by age, BMI, family history, stage, grade, histology, or tumor behavior (Table 2). A significant association $(\mathrm{p}=0.02)$ among 12 cases with grade 1 disease compared to 458 controls is likely due to chance, as the number of strata examined was large, sample size was small, no trend with grade was seen, and no biological explanation fits this observation.

\section{Discussion}

TCF7L2 has received much recent attention, as a consistently-replicated association that originated out of a traditional genetic linkage scan [3] that also appears consistently as a "top hit" for several phenotypes in genome-wide association studies [13]. Although association between rs 12255372 and risk of Type 2 diabetes is thought to be due to impairment of insulin secretion [14], TCF7L2 has also long been known to have a role in Wnt/ $\beta$-catenin signaling. Deregulation of the Wnt pathway is involved in the mechanisms of carcinogenesis [15], and mutations in Wnt-related genes have been detected in many cancers [16-18], indicating somatic mutations are important deregulation mechanisms of Wnt signaling. In breast cancer, we recently demonstrated that SNPs in the AXIN2 and APC genes are associated with risk [11]. In ovarian cancer, somatic mutations in CTNNB1 (encoding $\beta$-catenin) are directly linked to carcinogenic transformation, but they are rare and mostly found in endometrioid adenocarcinomas [19]. Ovarian expression studies show differences for distinct cellular components of the Wnt pathway between normal and cancer cells [20] implicating Wnt signaling in the molecular events leading to ovarian cancer despite the fact that gene mutations are uncommon [21].

Because of the importance of Wnt/ $\beta$-catenin signaling in breast and ovarian cancer, TCF7L2's critical role in combining with $\beta$-catenin, clear associations of rs 12255372 with non-cancer phenotypes, and suggestive evidence of association with cancer phenotypes, we hypothesized that genotypes at this SNP may be associated with risk of breast and/or ovarian cancer. However, no strong association was suggested in our analysis of almost 800 breast cancer cases and 850 controls, and almost 400 ovarian cancer cases and 450 controls.

These results contrast with a smaller analysis of 592 familial breast cancer cases and 735 controls which showed a per-allele OR of 1.19 (95\% CI 1.01-1.42) [6]. Our breast cancer case-control series provided $80 \%$ power to detect an OR as low as 1.22, assuming a minor allele frequency of 0.25 and a Type I error rate of 0.05 and was adequately

Table 2: TCF7L2 rs I 2255372 and risk of ovarian cancer

\begin{tabular}{|c|c|c|c|c|c|c|c|c|}
\hline & & \multirow{2}{*}{$\begin{array}{c}\mathbf{N} \\
\text { Cases }\end{array}$} & \multirow{2}{*}{$\begin{array}{c}\mathbf{N} \\
\text { Controls }\end{array}$} & \multicolumn{2}{|c|}{ Ordinal OR $(95 \% \mathrm{CI})$} & \multicolumn{3}{|c|}{ Co-Dominant ORs $(95 \% \mathrm{Cl})$} \\
\hline & & & & Per T-allele & $P$ (trend) & GT v GG & TT v GG & $P(2$ d.f. $)$ \\
\hline Total & --- & 391 & 458 & $0.96(0.77-I .20)$ & 0.75 & $0.95(0.7 I-I .26)$ & $0.97(0.56-1.68)$ & 0.93 \\
\hline \multirow[t]{2}{*}{ Age } & $<60$ & 191 & 206 & $1.15(0.83-1.59)$ & 0.40 & $1.04(0.68-1.58)$ & $1.60(0.70-3.69)$ & 0.54 \\
\hline & $60+$ & 200 & 252 & $0.82(0.60-1.10)$ & 0.19 & $0.87(0.58-1.28)$ & $0.60(0.28-1.28)$ & 0.38 \\
\hline \multirow[t]{2}{*}{ BMI } & $\leq 26.2$ & 164 & 226 & $1.00(0.72-1.39)$ & 1.00 & $0.96(0.62-1.47)$ & $1.08(0.47-2.44)$ & 0.96 \\
\hline & $>26.2$ & 211 & 203 & $0.94(0.69-1.30)$ & 0.74 & $0.98(0.65-1.49)$ & $0.84(0.38-1.84)$ & 0.91 \\
\hline Family & No & 329 & 403 & $0.93(0.74-1.18)$ & 0.58 & I.0I (0.74-I.37) & $0.77(0.43-1.38)$ & 0.66 \\
\hline history & Yes & 50 & 32 & $2.18(0.89-5.34)$ & 0.09 & $1.20(0.40-3.61)$ & $21.1(1.34-334)$ & 0.09 \\
\hline \multirow[t]{4}{*}{ Stage } & 1 & 103 & 458 & $1.00(0.70-1.4 I)$ & 0.99 & $0.95(0.60-1.50)$ & $1.08(0.44-2.63)$ & 0.96 \\
\hline & 2 & 29 & 458 & $1.24(0.65-2.35)$ & 0.51 & $1.09(0.49-2.4 \mathrm{I})$ & $2.25(0.28-17.8)$ & 0.74 \\
\hline & 3 & 196 & 458 & $0.86(0.66-1.13)$ & 0.28 & $0.82(0.58-1.18)$ & $0.80(0.4 \mid-1.56)$ & 0.52 \\
\hline & 4 & 55 & 458 & $1.26(0.78-2.02)$ & 0.35 & $1.54(0.82-2.89)$ & $1.07(0.35-3.26)$ & 0.40 \\
\hline \multirow[t]{5}{*}{ Grade } & 0 & 64 & 458 & $1.26(0.80-1.99)$ & 0.32 & $1.12(0.64-1.95)$ & $2.34(0.52-10.4)$ & 0.52 \\
\hline & 1 & 12 & 458 & $0.37(0.16-0.88)$ & 0.02 & $0.19(0.04-0.94)$ & $0.15(0.02-1.11)$ & 0.09 \\
\hline & 2 & 41 & 458 & $0.88(0.53-1.46)$ & 0.62 & $1.09(0.54-2.23)$ & $0.6 \mathrm{I}(0.2 \mathrm{I}-\mathrm{I} .8 \mathrm{I})$ & 0.60 \\
\hline & 3 & 146 & 458 & $0.99(0.73-1.35)$ & 0.94 & $0.97(0.65-1.44)$ & $1.02(0.46-2.27)$ & 0.98 \\
\hline & 4 & 121 & 458 & $0.93(0.68-1.29)$ & 0.68 & $0.93(0.60-1.42)$ & $0.89(0.40-1.98)$ & 0.92 \\
\hline \multirow[t]{5}{*}{ Histology } & Serous & 232 & 458 & $0.93(0.72-1.21)$ & 0.60 & $0.87(0.62-1.21)$ & $1.00(0.52-1.93)$ & 0.70 \\
\hline & Mucinous & 27 & 458 & $1.24(0.63-2.44)$ & 0.53 & $0.89(0.40-1.97)$ & n.a. & 0.96 \\
\hline & Endometriod & 64 & 458 & $0.94(0.62-1.4 I)$ & 0.76 & $1.55(0.84-2.86)$ & $0.53(0.23-1.22)$ & 0.07 \\
\hline & Clear cell & 25 & 458 & $1.04(0.54-2.00)$ & 0.91 & $0.81(0.35-1.90)$ & $1.91(0.23-15.7)$ & 0.70 \\
\hline & Mixed cell & 32 & 458 & $1.42(0.76-2.68)$ & 0.27 & $1.30(0.60-2.80)$ & $2.73(0.35-21.4)$ & 0.55 \\
\hline \multirow[t]{2}{*}{ Behavior } & Malignant & 327 & 458 & $0.93(0.74-1.17)$ & 0.52 & $0.92(0.68-1.25)$ & $0.87(0.49-1.53)$ & 0.81 \\
\hline & Borderline & 64 & 458 & $1.20(0.76-1.88)$ & 0.43 & I.03 (0.59-I.80) & $2.29(0.52-10.2)$ & 0.55 \\
\hline
\end{tabular}

BMI, body mass index, categorized by median value; family history, first-degree or second-degree family history; analyses adjusted for age (unless used as stratifiying variable) and region of residence; n.a., not estimatable, bold indicates $p<0.05$. 
powered to detect similar modest associations. Additionally, there may be an association in smaller subsets consistent with non-luminal tumors. No ovarian cancer analyses have been reported to date. Previous reports in other traits suggested varied association by BMI, family history, and tumor features; although subset sample sizes were small, we found no evidence for association between rs12255372 and risk in any subset.

\section{Conclusion}

Despite strong prior evidence that this SNP may play a role women's cancer susceptibility, we conclude that variation in TCF7L2 is not likely to be associated with risk of non-familial breast cancer or ovarian cancer. Because very modest associations could not be definitively ruled out and because increased risk may exist for triple-negative breast cancer cases, much larger studies will be required for more precise estimation of rs 12255372 's role in cancer susceptibility. In addition, given the role of $\mathrm{Wnt} / \beta$-catenin signaling in cancer, identified associations of SNPs in the AXIN2 and APC genes with breast cancer and the increased risk conferred by family history for these conditions even after accounting for known syndromes, additional SNPs and genes within this pathway warrant further study.

\section{Competing interests}

The authors declare that they have no competing interests.

\section{Authors' contributions}

ELG drafted the manuscript and oversaw the ovarian cancer study; CS initiated the collaboration and guided subset analysis; LP-O provided preliminary results and interpreted results; RAV supervised ovarian cancer analysis; ZSF performed breast cancer analysis; FSC provided key interpretive insight; KLW compiled results and performed literature review; MS performed ovarian cancer analysis; BLF oversaw ovarian cancer analysis; and FJC oversaw the breast cancer study.

\section{Acknowledgements}

This work was supported, in part, by funding from the Mayo foundation and ROI CAI 22443.

\section{References}

I. Reynisdottir I, Thorleifsson G, Benediktsson R, Sigurdsson G, Emilsson V, Einarsdottir AS, Hjorleifsdottir EE, Orlygsdottir GT, Bjornsdottir GT, Saemundsdottir J, et al.: Localization of a susceptibility gene for type 2 diabetes to chromosome 5q34-q35.2. Am J Hum Genet 2003, 73(2):323-335.

2. Duggirala R, Blangero J, Almasy L, Dyer TD, Williams KL, Leach RJ, $O$ 'Connell $P$, Stern MP: Linkage of type 2 diabetes mellitus and of age at onset to a genetic location on chromosome $10 \mathrm{q}$ in Mexican Americans. Am J Hum Genet 1999, 64(4): I I 27-I I 40.

3. Grant SF, Thorleifsson G, Reynisdottir I, Benediktsson R, Manolescu A, Sainz J, Helgason A, Stefansson H, Emilsson V, Helgadottir A, et al.: Variant of transcription factor 7-like 2 (TCF7L2) gene confers risk of type 2 diabetes. Nat Genet 2006, 38(3):320-323.

4. Cauchi S, El Achhab Y, Choquet H, Dina C, Krempler F, Weitgasser $R$, Nejjari C, Patsch W, Chikri M, Meyre D, et al.: TCF7L2 is repro- ducibly associated with type 2 diabetes in various ethnic groups: a global meta-analysis. J Mol Med 2007, 85(7):777-782.

5. Cauchi S, Choquet H, Gutierrez-Aguilar R, Capel F, Grau K, Proenca C, Dina C, Duval A, Balkau B, Marre M, et al.: Effects of TCF7L2 polymorphisms on obesity in European populations. Obesity (Silver Spring) 2008, I 6(2):476-482.

6. Burwinkel B, Shanmugam KS, Hemminki K, Meindl A, Schmutzler RK, Sutter C, Wappenschmidt B, Kiechle M, Bartram CR, Frank B: Transcription factor 7-like 2 (TCF7L2) variant is associated with familial breast cancer risk: a case-control study. BMC Cancer 2006, 6:268.

7. Agalliu I, Suuriniemi M, Prokunina-Olsson L, Johanneson B, Collins FS, Stanford JL, Ostrander EA: Evaluation of a variant in the transcription factor 7-like 2 (TCF7L2) gene and prostate cancer risk in a population-based study. Prostate 2008, 68(7):740-747.

8. Hazra A, Fuchs CS, Chan AT, Giovannucci EL, Hunter DJ: Association of the TCF7L2 polymorphism with colorectal cancer and adenoma risk. Cancer Causes Control 2008, 19(9):975-980.

9. Folsom AR, Pankow JS, Peacock JM, Bielinski SJ, Heiss G, Boerwinkle $E$ : Variation in TCF7L2 and increased risk of colon cancer: the Atherosclerosis Risk in Communities (ARIC) Study. Diabetes Care 2008, 3 I (5):905-909.

10. Slattery ML, Folsom AR, Wolff R, Herrick J, Caan BJ, Potter JD: Transcription factor 7-like 2 polymorphism and colon cancer. Cancer Epidemiol Biomarkers Prev 2008, I 7(4):978-982.

II. Wang X, Goode EL, Fredericksen ZS, Vierkant RA, Pankratz VS, LiuMares W, Rider DN, Vachon CM, Cerhan JR, Olson JE, et al.: Association of genetic variation in genes implicated in the betacatenin destruction complex with risk of breast cancer. Cancer Epidemiol Biomarkers Prev 2008, 17(8):2101-2108.

12. Kelemen LE, Sellers TA, Schildkraut JM, Cunningham JM, Vierkant RA, Pankratz VS, Fredericksen ZS, Gadre MK, Rider DN, Liebow M, et al.: Genetic variation in the one-carbon transfer pathway and ovarian cancer risk. Cancer Res 2008, 68(7):2498-2506.

13. Bosse Y, Bacot F, Montpetit A, Rung J, Qu HQ, Engert JC, Polychronakos C, Hudson T], Froguel P, Sladek R, et al.: Identification of susceptibility genes for complex diseases using pooling-based genome-wide association scans. Hum Genet 2009, I 25(3):305-318.

14. Stolerman ES, Manning AK, McAteer JB, Fox CS, Dupuis J, Meigs JB, Florez JC: TCF7L2 variants are associated with increased proinsulin/insulin ratios but not obesity traits in the Framingham Heart Study. Diabetologia 2009, 52(4):6 | 4-620.

15. Reya $T$, Clevers $H$ : Wnt signalling in stem cells and cancer. Nature 2005, 434(7035):843-850.

16. Powell SM, Zilz N, Beazer-Barclay Y, Bryan TM, Hamilton SR, Thibodeau SN, Vogelstein B, Kinzler KW: APC mutations occur early during colorectal tumorigenesis. Nature 1992, 359(6392):235-237.

17. Ozaki S, Ikeda S, Ishizaki $Y$, Kurihara T, Tokumoto N, Iseki M, Arihiro $\mathrm{K}$, Kataoka T, Okajima M, Asahara T: Alterations and correlations of the components in the Wnt signaling pathway and its target genes in breast cancer. Oncol Rep 2005, 1 4(6): | 437- I 443.

18. Gerstein AV, Almeida TA, Zhao G, Chess E, Shih le M, Buhler K, Pienta K, Rubin MA, Vessella R, Papadopoulos N: APC/CTNNB I (beta-catenin) pathway alterations in human prostate cancers. Genes Chromosomes Cancer 2002, 34(1):9-16.

19. Kurman RJ, Shih le M: Pathogenesis of ovarian cancer: lessons from morphology and molecular biology and their clinical implications. Int J Gynecol Pathol 2008, 27(2):15I-160.

20. Badiglian Filho L, Oshima CT, De Oliveira Lima F, De Oliveira Costa H, De Sousa Damiao R, Gomes TS, Goncalves WJ: Canonical and noncanonical Wnt pathway: A comparison among normal ovary, benign ovarian tumor and ovarian cancer. Oncol Rep 2009, 2 I (2):3। 3-320

21. Gatcliffe TA, Monk BJ, Planutis K, Holcombe RF: Wnt signaling in ovarian tumorigenesis. Int J Gynecol Cancer 2008, I 8(5):954-962.

\section{Pre-publication history}

The pre-publication history for this paper can be accessed here:

http://www.biomedcentral.com/1471-2407/9/312/pre

pub 